\title{
A Novel Arsenic Filtration System for Low-Income Families in Rural Bangladesh
}

\author{
Ishraq A. Haque \\ Academic Magnet High School, 5109 Enterprise St, North Charleston, SC, 29405, USA; ishraqhaque101@gmail.com
}

\begin{abstract}
Over 200 million people globally are affected by arsenic-contaminated water. Moreover, groundwater from tube wells is often contaminated with arsenic which, if ingested, can result in diarrhea, blood vessel diseases, and cancers. Arsenic filtration processes, like the SONO filter, 3-Kolshi filter, and ion exchange methods are promising developments that significantly reduce arsenic levels. However, cost, maintenance, and availability of these methods prevent many low-income families from using them. The aim of this project is to engineer a novel filtration system that significantly reduces arsenic and is maintainable and affordable for poverty-stricken populations. In this project, laterite soil was substituted for iron as the method of arsenic filtration to reduce costs. Through analysis, the constructed One Step Red Soil Filtration (OSRSF) was found superior to the 3-Kolshi filter, making it an economically beneficial option for poor people to have safe drinking water.

KEYWORDS: Chemistry; Arsenic; SONO filter; Composite Iron Matrix (CIM); Tube Well Water; 3-Kolshi; One Step Red Soil Filtration (OSRSF); Laterite Soil; Bangladesh.
\end{abstract}

\section{- Introduction}

Arsenic is an element from within the Earth's crust and can contaminate water. In its inorganic form it is extremely toxic. ${ }^{1-3}$ Arsenic-contaminated water is an exceedingly prevalent occurrence in rural areas. In these areas, families use tube wells to pump out groundwater, which is often contaminated. ${ }^{1,2}$ Because of this, over 200 million people drink high levels of arsenic-contaminated water. ${ }^{4}$ High concentrations of arsenic can lead to arsenic poisoning, a health issue in countries like Chile, India, and Bangladesh. ${ }^{1}$ Arsenic poisoning causes complications such as diarrhea, affected hair and nails, darkened skin tone, and skin and bladder cancer. ${ }^{1,5-8}$ The World Health Organization (WHO) and the Human Rights Watch have named Bangladesh a country largely affected by arsenic-contaminated water, so this study was held in Bangladesh to find a new approach to reducing arsenic levels in the water for poor people. In Bangladesh, over 20 million people drink arsenic-contaminated water and over 43,000 people die from arsenic related illnesses annually. ${ }^{6,8}$

Research into reducing arsenic levels in groundwater has been conducted in several countries. Filtration is the most viable solution to removing arsenic from water. ${ }^{9}$ In 2006, Bangladeshi chemist and professor Abul Hussam invented the SONO Arsenic Filter to filter tube well water. The filter is made of 3 stacked buckets filled with coarse river sand, a 4-5 $\mathrm{cm}$ thick layer of a specifically designed composite iron matrix (CIM), charcoal, and wet brick chips. By pouring water through the buckets, large particles are filtered through the sand, arsenic is removed through chemical reactions in the CIM, and the charcoal and wet brick chips remove organics. The creation of the SONO filter has led to a significant decrease in arsenic levels in drinking water and has been implemented in many villages. ${ }^{10,11}$
While the SONO filter has had unprecedented success, it does have several drawbacks. A questionnaire administered in rural Bangladeshi villages revealed problems such as breakage, maintenance issues, high cost, weak sludge-disposal guidance, and slow flow rate of filtered water. ${ }^{12}$ Alternative household tube wells have since been developed, but these also have issues with slow water release as well as complicated set-up and main tenance. ${ }^{13,14}$ Additionally, many Bangladeshi villagers have a daily income of less than five USD, so the 60-70 USD replace ment filter cartridges is unaffordable.

The CIM, where the arsenic is removed, is considered very beneficial for the SONO filter. It works using the following chemical reactions: ${ }^{10}$

Equation 1: $\mathrm{FeOH}+\mathrm{H}_{2} \mathrm{AsO}_{4}{ }^{-} \rightarrow \mathrm{FeHAsO}_{4}{ }^{-}+\mathrm{H}_{2} \mathrm{O}$

$\left(\mathrm{K}=10^{24)}\right.$

Equation 2: $\mathrm{FeOH}+\mathrm{HAsO}_{4}{ }^{2-} \rightarrow \mathrm{FeHAsO}_{4}{ }^{2-}+\mathrm{H}_{2} \mathrm{O}$

$\left(\mathrm{K}=10^{29}\right)$

Based on existing literature, the author hypothesized that applying laterite soil, commonly known as red soil, is lieu of an iron matrix will remove arsenic. ${ }^{14}$ To test this hypothesis, a one-step arsenic filter was developed that was economic and efficient in lowering arsenic levels in water to a safe range. While CIM is the most efficient way to remove arsenic, pov erty-stricken families cannot afford to maintain the SONO filters. The author invented a novel approach, called One Step Red Soil Filtration (OSRSF). Water sampling, testing, and data collection came from a small village in Assasuni Upazila of the Satkhira District in Bangladesh (Figure 1). This study presented a filter consisting of laterite soil and sand, cloth, charcoal, and brick chips (Figure 2).

This study aims to reduce arsenic in water to a tolerable lev el for poor people unlike other filters that significantly reduce arsenic levels to WHO standards. ${ }^{1,8}$ 

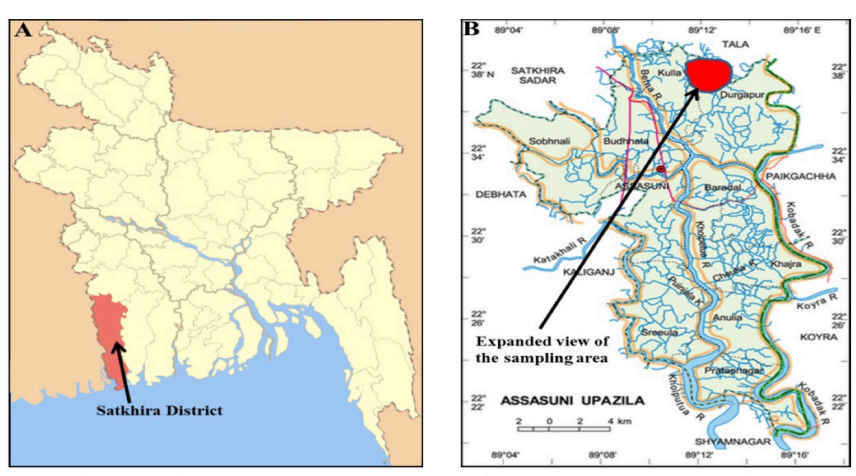

Figure 1: A map of arsenic-conteminated area in Satkhira District, Bangladesh from where water samples were taken. (A) Bangladesh map with Stahkira district highlighted. (B) Expanded view of Assasuni Upazila highlighting the study area. Map A was adapted from Wikipedia and Map B was adapted from WordPress.com.

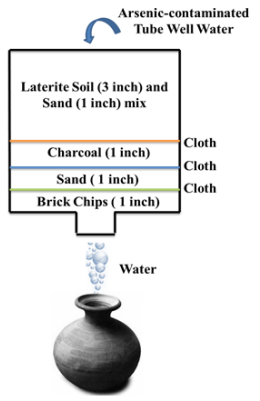

Figure 2: Development of a novel filtration system to reduce arsenic in tube well water.

\section{- Methods}

Before implementing the novel OSRSF, collecting water samples from a low-income region was essential. Data collection occurred in a small village in Bangladesh where samples from thirty tube wells were collected. The arsenic concentrations were measured in each sample using the Hach EZ Arsenic High Range Test Kit. The kit included test strips, a reaction bottle and cap, two reagents, and a comparison chart (Figure 4). A test strip containing mercuric bromine was inserted into the special cap that locks onto the strip. A reaction bottle was filled with $50 \mathrm{~mL}$ sample water. The two reagents, labeled "Reagent 1" and "Reagent 2" by Hach, were added to trigger sulfamic acid crystals to acidify the sample. The cap was attached to the bottle and swirled for one minute and then left for 40 minutes to react, the liquid being swirled twice. ${ }^{16,17}$ During this time, the air reacted with the sample solution and imprinted the product on the test strip. ${ }^{17}$ After the reaction time was over, the test strip was removed and compared to the chart to determine the arsenic concentration in parts per billion (ppb) in the sample. This process was repeated for each sample.

The OSRSF was held in a tin, octagonal prism with a height and diameter of 7" and the whole system was enclosed in a tin, octagonal prism with a height of 25 " and a diameter of 10 ". A plastic stand held the filtration system in the larger tin container. The OSRSF included a 4" layer of the 3:1 laterite soil to sand ratio, a 1" layer of charcoal, a 1" layer of sand, and a 1" layer of brick chips. All the layers were separated by sari cloth (Figure 2, Figure 5).
Three liters of each sample, $100 \mathrm{ppb}, 250 \mathrm{ppb}$, and $500 \mathrm{ppb}$, were collected and filtered through the OSRSF. Filtration took approximately 45 minutes for each sample. The filtered water was then collected in a kolshi, is the traditional vessel used in Bangladesh to collect and carry water (Figure 5). The author tested the OSRSF and the 3-kolshi system with the most prevalent concentrations: $100 \mathrm{ppb}, 250 \mathrm{ppb}$, and $500 \mathrm{ppb}$. The 3-kolshi system was considered the control.

\section{Statistical Analysis:}

Statistical analyses were performed by the author's t-test. Any p-value less than or equal to 0.05 is considered statistically significant.

\section{- Results}

\section{Testing arsenic levels:}

Tube well water samples were taken to find the range of arsenic concentrations in the Satkhira village region. With the villagers' consent, 30 tube wells were selected and marked for this project (Figure 3). Water samples were then collected and tested using the Hach EZ Arsenic High Range Test Kit.

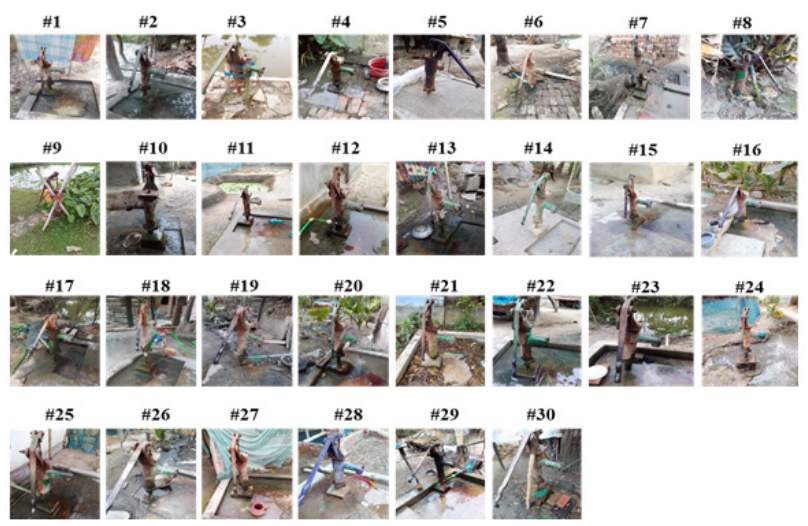

Figure 3: Arsenic concentrations tested from 30 tube wells in a rural village in Bangladesh.

Information about the samples, including the well's owner, the depth, the arsenic concentrations, and a comment on the concentrations, were recorded (Table 1). The study's participants are not well educated, so providing information about the arsenic levels as well as the local guidelines for arsenic-contaminated water is helpful to them. The maximum arsenic concentration measured was $500 \mathrm{ppb}$. Twelve samples had a $250 \mathrm{ppb}$ concentration, and fifteen had a concentration of $100 \mathrm{ppb}$ (Table 1). The tube well depths were measured to test a correlation between arsenic levels and well depth, which was not found.

\section{Testing OSRSF :}

Arsenic levels were measured using Hach EZ Arsenic High Range Test Kit (Fig. 4). By using OSRSF (Figure 5), arsenic concentrations of tube well water could be reduced to a at least $50 \mathrm{ppb}$, the safe level according to Bangladeshi regulations. ${ }^{1}$ WHO sets a much lower threshold, $10 \mathrm{ppb}$, for drinkable water, but the Bangladeshi government set their own standard for rural populations because they drink tube well water that contains extremely high levels of arsenic.

The OSRSF was first tested with sample of $250 \mathrm{ppb}$ concentration. In one filtration, the concentration dropped to $50 \mathrm{ppb}$ 
(Figure 6). A $100 \mathrm{ppb}$ concentration sample was reduced to $25 \mathrm{ppb}$ with one filtration of the OSRSF (Figure 7). A third trial was done a 500-ppb sample, the maximum arsenic level measured. The sample required two filtrations to reach the acceptable limit. The first run through lowered the concentra-

Table 1: Tube well depth and arsenic concentration in tube well water.

\begin{tabular}{|c|c|c|c|c|}
\hline $\begin{array}{l}\text { Tube } \\
\text { Well }\end{array}$ & Owner & $\begin{array}{l}\text { Depth } \\
\text { (feet) }\end{array}$ & $\begin{array}{l}\text { Arsenic } \\
\text { Conc. } \\
\text { (ppb) }\end{array}$ & Comment \\
\hline 01 & Abul Khaer & 220 & 250 & High \\
\hline 02 & Mohidul Mallik & 200 & 250 & High \\
\hline 03 & Alimuddin Sardar & 160 & 100 & Moderately high \\
\hline 04 & Ebadul Sardar & 200 & 500 & Very high \\
\hline 05 & Asadul Islam & 220 & 250 & High \\
\hline 06 & Shahidul Islam & 200 & 500 & Very high \\
\hline 07 & Nazrul Islam & 200 & 250 & High \\
\hline 08 & Majed Dhali & 200 & 100 & Moderately high \\
\hline 09 & Alamgir Hossain & 200 & 500 & Very high \\
\hline 10 & Abubakar Siddique & 200 & 250 & High \\
\hline 11 & Shahidul Islam & 200 & 100 & Moderately high \\
\hline 12 & Mizanur Dhali & 240 & 250 & High \\
\hline 13 & Mizanur Rahman & 200 & 100 & Moderately high \\
\hline 14 & Shahaban Sardar & 200 & 100 & Moderately high \\
\hline 15 & Hachim Sardar & 180 & 100 & Moderately high \\
\hline 16 & Nurul Sardar & 180 & 100 & Moderately high \\
\hline 17 & Faruq Hossain & 200 & 100 & Moderately high \\
\hline 18 & Monarul Islam & 200 & 100 & Moderately high \\
\hline 19 & Sayed Mali & 200 & 250 & High \\
\hline 20 & Aktarul Islam & 180 & 100 & Moderately high \\
\hline 21 & Abdul Qafi & 200 & 100 & Moderately high \\
\hline 22 & Zahiruddin Dhali & 220 & 250 & High \\
\hline 23 & Abdul Quddus & 150 & 100 & Moderately high \\
\hline 24 & Mfizul Islam & 150 & 250 & High \\
\hline 25 & Radwan Mehedi & 200 & 100 & Moderately high \\
\hline 26 & Mukter Hossain & 200 & 100 & Moderately high \\
\hline 27 & Emdadul Hossain & 200 & 250 & High \\
\hline 28 & Abdul Hai & 220 & 100 & Moderately high \\
\hline 29 & Khalil Sardar & 200 & 250 & High \\
\hline 30 & Amjed Sardar & 200 & 250 & High \\
\hline
\end{tabular}
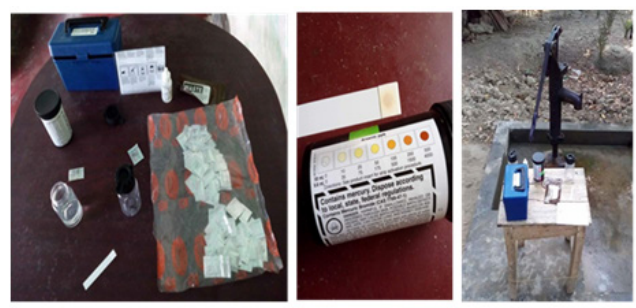

Figure 4: Materials for testing arsenic concentrations in tube well water.

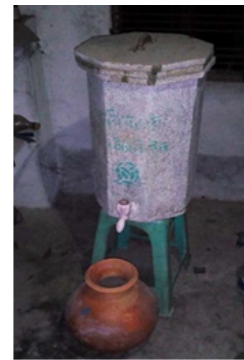

Figure 5: Picture of the newly developed OSRSF.

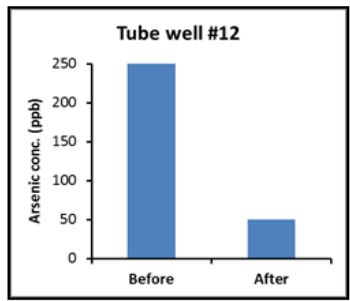

Figure 6: Bar graphs depicts before and after filtering with OSRSF on a $250 \mathrm{ppb}$ sample from tube well \#12. For $250 \mathrm{ppb}$ sample, OSRSF was effective in bringing arsenic level down to $50 \mathrm{ppb}$.

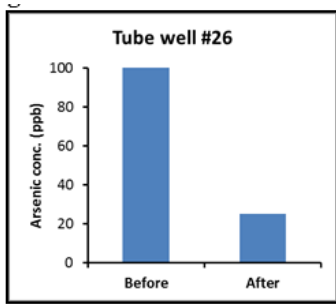

Figure 7: Bar graph depicts before and after filtering with OSRSF on a $100 \mathrm{ppb}$ sample from tube well \#26. For 100 ppb sample, OSRSF was effective in bringing arsenic level down to $25 \mathrm{ppb}$. tion to $100 \mathrm{ppb}$, and the second filtration lowered it again to $25 \mathrm{ppb}$ (Figure 8).

\section{Comparison of OSRSF with existing filtration system:}

The OSRSF system was compared to a locally made 3-kolshi system. The 3-kolshi filter also required two run throughs to get a $500 \mathrm{ppb}$ concentration down to an acceptable level (Figure 8). Three liters of water were poured into each system and about 2.8 liters came out for both. For the 500-ppb concentration, the filtered water from the 3-kolshi system had $200 \mathrm{ppb}$ after the first filtration whereas the water filtered using the OSRSF had a concentration of 100 ppb (Fig. 8). The difference between the results is noticeable from just the first filtration. During the second filtration the OSRSF brought the concentration from $100 \mathrm{ppb}$ to $25 \mathrm{ppb}$, and the 3-kolshi brought the concentration from $200 \mathrm{ppb}$ to $50 \mathrm{ppb}$, which is still an acceptable arsenic level for Bangladesh. The OSRSF and the 3-kolshi both yielded identical results for the $100 \mathrm{ppb}$ and $250 \mathrm{ppb}$ samples.

Statistical analyses and calculations were performed on the $250 \mathrm{ppb}$ concentration samples (Figure 9). The average concentration after filtering through the 3-kolshi system was $43.75 \mathrm{ppb}$ while the average concentration after OSRSF was $41.66 \mathrm{ppb}$. The 3-kolshi system's standard deviation was 11.31 and 12.31 for the OSRSF. The t-test was used to calculate the statistical significance. The $\mathrm{p}$-value was 0.36 , so there was no
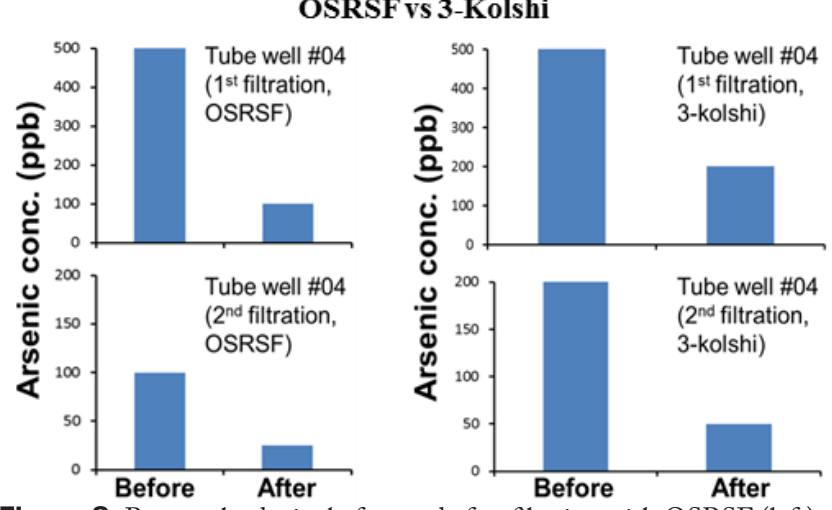

Figure 8: Bar graphs depict before and after filtering with OSRSF (left) a 3-kolshi (right) on a $500 \mathrm{ppb}$ sample from tube well \#04. Results suggest that the second filtration by OSRSF was very effective in making the water sample drinlable in terms of Bangladeshi rules and regulations.

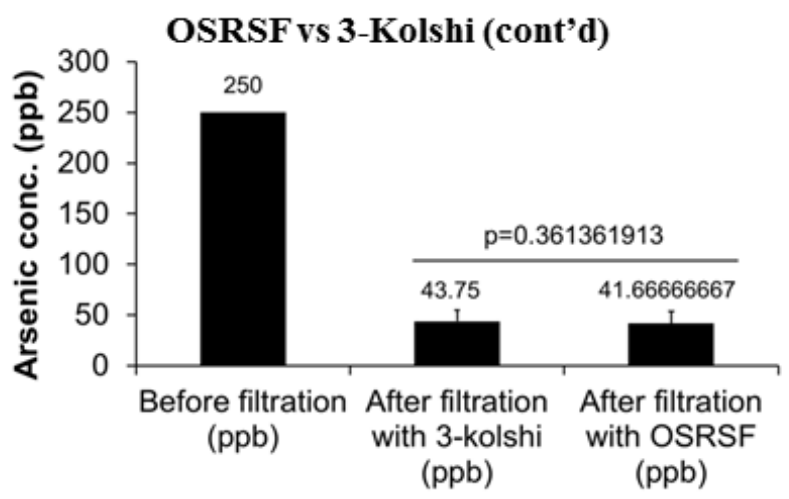

Figure 9: Bar graphs depicts arsenic levels before and after filtering with 3-kolshi and OSRSF. Statistical analysis suggests that water samples obtained from OSRF were comparable to 3-kolshi and can be economically beneficial for low income rural populations. 
statistical significance. However, the data suggests the OSRSF and the 3-kolshi systems are equally as effective.

\section{- Discussion}

It was observed that the OSRSF system filtered arsenic better than the locally used 3-kolshi system. There is no statistical significance in using either the 3-kolshi system or the OSRSF (Figure 9). However, the OSRSF is realistically superior. It is the much cheaper option, and many villagers reported the OSRSF to be easier in use and maintenance via a questionnaire. Based on this data, the laterite soil may be able to better handle high levels of arsenic in comparison to iron chips found in the 3-kolshi even with the drawbacks of the soil.

The project is strengthened due to the OSRSF's low cost. It is cheaper than either the SONO filter or the 3-kolshi system. The total construction of the OSRSF was approximately 3 USD while the 3-kolshi production cost was reported by Satkhira villagers as 10 USD. The laterite soil needed to maintain the OSRSF is available in Satkhira for free. The tin containers are approximately 2 USD, and the charcoal and brick chips are less than 1 USD. Additionally, OSRSF owners may use a private collection of any of the needed materials. It is recommended the filter soil be replaced weekly to restore the amount of iron in the filter.

Compared to similar systems like the SONO filter and the 3-kolshi system, the OSRSF is cheaper, easier to maintain, and can be easily reproduced without a custom iron matrix. The 3 -kolshi is effective, but the OSRSF is superior in usage, affordability, and efficiency. The OSRSF may not filter arsenic as well as the SONO filter, which can reduce levels to less than $10 \mathrm{ppb} 1$, and was also not tested in this study. This study is novel in its application of a one-step filtration system for the poor that exploits the natural iron content in the local soil.

There are some limitations to the OSRSF. It takes approximately 45 minutes to filter water and only small amounts of water can be filtered at a time. While the OSRSF is not currently large-scale, one could recreate a proportionally scaled OSRSF to filter more water. Another concern is the possibility of pathogens in the filtered water due to the laterite soil. If such a problem occurs, boiling the filtered water can kill harmful pathogens.

\section{- Conclusions}

This novel filtration system is economical for poverty-stricken populations to afford and maintain safe drinking water. The quality of life is improved for rural, low-income populations through this filtration system. Based on the results of this study, several conclusions were made on the OSRSF's effectiveness:

1) The OSRSF reduces arsenic levels of up to $500 \mathrm{ppb}$ down to the Bangladeshi safe standard of $50 \mathrm{ppb}$. The 500-ppb sample had to be filtered twice to reach the safe level using the OSRSF, but it occurred in the 3-kolshi system as well.

2) The OSRSF is economically advantageous for poverty-stricken people, costing about 3 USD.

3) Laterite soil seems to be an acceptable replacement to the SONO filter's CIM and the 3-kolshi system's iron chips for low-income populations in Satkhira because laterite soil is readily available in that area.
4) Limitations of the OSRSF include no large-scale usage, slow water flow, and possible pathogenic contamination.

The future of the study may include finding an alternative to laterite soil for areas with a little to no laterite soil so the residents can still have an affordable arsenic water filter. Participants of the study have continued using the OSRSFs implemented in their village, and so examination of their hair and nails as well as skin status could be useful. Testing these may indicate a health improvement in the population, and it would also allow comparison between the health of OSRSF users versus users of other filters and/or those who do not use filters.

In summary, this project devised an alternative arsenic filtration system for poverty-stricken people and reduced the arsenic levels in contaminated water to a tolerable level. With the OSRSF system, the poor can drink safe water that will improve their quality of life, and the implementation of the OSRSF in other villages can improve rural quality of life around the world.

\section{Acknowledgements}

I would first like to thank my parents for their support throughout this project. I would also like to thank MR. Nazmul Haque and Mr. Redwan Mehidi who helped me interact with local villagers to collect water samples. I would also like to thank Mr. Rafiqul Haque for assisting me in gathering information about arsenic-affected populations in rural Bangladesh as well as helping me construct the OSRSF. I would finally like the participants of my study who allowed me access to their tube wells. Without these contributions, this project would not have been possible.

\section{References}

1. Arsenic.https://www.who.int/en/news-room/fact-sheets /detail/arsenic (accessed Sep 22, 2019).

2. Flanagan, S. V.; Johnston, R. B.; Zheng, Y. Arsenic in Tube Well Water in Bangladesh: Health and Economic Impacts and Implications for Arsenic Mitigation. Bulletin of the World Health Organization 2012, 90 (11), 839-846.

3. Water Treatment Solutions. https://www.lenntech.com /periodic/elements/as.htm (accessed Sep 22, 2019).

4. George, C. M.; Sima, L.; Arias, M. H. J.; Mihalic, J.; Cabrera, L. Z.; Danz, D.; Checkley, W.; Gilman, R. H. Arsenic Exposure in Drinking Water: An Unrecognized Health Threat in Peru. Bulletin of the World Health Organization 2014, 92 (8), 565-572.

5. Mandal, B. K.; Ogra, Y.; Suzuki, K. T. Speciation of Arsenic in Human Nail and Hair from Arsenic-Affected Area by HPLC-Inductively Coupled Argon Plasma Mass Spectrometry. Toxicology and Applied Pharmacology 2003, 189 (2), 73-83.

6. Uddin, R.; Huda, N. H. Arsenic Poisoning in Bangladesh. Oman Medical Journal 2011, 26 (3), 207.

7. Smith, A. H.; Lingas, E. O.; Rahman, M.

Contamination of Drinking-Water by Arsenic in Bangladesh: A Public Health Emergency. Bulletin of the World Health Organization 2000, 78 (9), 1093-1103.

8. Das, N. K.; Sengupta, S. R. Arsenicosis: Diagnosis and Treatment. Indian Journal of Dermatology, Venereology and Leprology 2008, 74 (6), 571-581. 
9. Hussam, A.; Munir, A. K. M. A Simple and Effective Arsenic Filter Based on Composite Iron Matrix: Development and Deployment Studies for Groundwater of Bangladesh. Journal of Environmental Science and Health, Part A: Toxic/Hazardous Substances and Environmental Engineering 2007, 42 (12), 287-303.

10. Ashraf, S. Pittsburgh Post-Gazette. PG Publishing Company August 7, 2007.

11. Shafiquzzaman, M.; Azam, M. S.; Mishima, I.; Nakajima, J. Technical and Social Evaluation of Arsenic Mitigation in Rural Bangladesh. Journal of Health, Population and Nutrition 2009, 27 (5), 674-683.

12. Munir, A. K. M.; Rasul, S. B.; Habibuddowla, M.; Alauddin, M.; Hussam, A.; Khan, A. H. Evaluation of Performance of Sono 3-Kolshi Filter for Arsenic Removal from Groundwater Using Zero Valent Iron through Laboratory and Field Studies. Proceedings International Workshop on Technology for Arsenic Removal from Drinking Water, Bangladesh University of Engineering and Technology and United Nations University, Japan 2005, 171-189.

13. Delowar, H. K. M.; Uddin, I.; E1 Hassan, W. H. A.; Perveen, F.; Irshad, M.; Islam, A. F. M. S.; Yoshida, I. A Comparative Study of Household Groundwater Arsenic Removal Technologies and Their Water Quality Parameters. Journal of Applied Sciences 2006, 6 (10), 2193-2200.

14. Maji, S. K.; Pal, A.; Pal, T. Arsenic Removal from Aqueous Solutions by Adsorption on Laterite Soil. Journal of Environmental Science and Health, Part A: Toxic/ Hazardous Substances and Environmental Engineering 2007, 42 (4), 453-462.

15. EZ Arsenic High Range Test Kit. https:/www.hach.com/ez-arsenic-high-range-test-kit/ product?id=7640217305 (accessed Sep 22, 2019).

16. George, C. M.; Zheng, Y.; Graziano, J. H.; Rasul, S. B.; Hossain, Z.; Mey, J. L.; Geen, A. V. Evaluation of an Arsenic Test Kit for Rapid Well Screening in Bangladesh. Environmental Science \& Technology 2012, 46 (20), 11213-11219.

17. Van Geen, A.; Cheng, Z.; Seddique, A. A.; Hoque, M. A.; Gelman, A.; Graziano, J. H.; Ahsan, H.; Parvez, F.; Ahmed, K. M. Reliability of a Commercial Kit to Test Groundwater for Arsenic in Bangladesh. Environmental Science \& Technology 2005, 39 (1), 299-303.

\section{- Author}

Ishraq Haque is a senior at the Academic Magnet High School in North Charleston, South Carolina. Ishraq has been fascinated by science his whole life. He is inspired by his mother, a research specialist in in neurology, and his father, a professor of microbiology and immunology, to pursue a career in science. He is part of his school's science club, works with bone scientists in a nearby medical university and completed a project with them. Outside of school, Ishraq is an avid martial artist, a pianist, a violinist, a published poet, and a volunteer for a local children's museum. Ishraq wants to become a physician scientist in the medical field and help people around the world. 